\title{
Measurements of Basic Performances for Waterjet Propulsion Systems in Water Tunnel
}

\author{
NOBUYUKI FUJISAWA \\ Department of Mechanical Engineering, Gunma University, 1-5-1 Tenjin, Kiryu, Japan, 376
}

\begin{abstract}
Experimental techniques are described in detail for evaluating the system and the unit performances of waterjet propulsion systems in a water tunnel. The measured performances of pump and propulsion of the model systems are in reasonable agreement with the field experiment with prototype craft. Measurements are also made for the losses in the intake and the nozzle. The optimization study of the water jet systems is conducted by simulating the change of the nozzle outlet diameter with the variable nozzle arrangement. It is suggested that the nozzle outlet diameter should be decreased as the craft velocity increases to obtain an optimum propulsive efficiency in a wide range of craft velocity.
\end{abstract}

Key Words: Waterjet system; Propulsion; Performance; Model experiment; Water tunnel; Optimization

\section{INTRODUCTION}

$\mathbf{P}$ ropulsion of the water craft by inducting water through on board pumps and ejecting it aft with an increase in momentum is termed waterjet propulsion. This type of propulsion offers distinct advantages over other types for applications to water craft designed for operation at high speed, for employment in shallow or weed-infested waters, and for safeguard of life against the propeller injury.

In order to investigate into the performance of the waterjet systems, the unit performances such as the intake, the pump, and the nozzle are important characteristics of the waterjet propulsion. However, the measurement of these unit performances of the waterjet systems during cruising has not been studied enough in a literature, because of the difficulty for measuring such performance of each unit by the prototype experiment due to the economical or geometrical limitations. Therefore, instead of the prototype experiment, the model experiment is carried out and they provide some informations on the intake, such as the losses, pressure distributions and the velocity profiles, as is reported by Wilson [1977], Haglund et al. [1982], Kashiwadani [1985, 1986], Fujisawa et al. [1990], and others.

The selection of the system units such as the intake, the pump and the nozzle is an important problem for the design of the waterjet systems with high propulsive efficiency, which has been discussed by Brandau [1968], Barr and Etter [1975], Etter [1976], Etter et al. [1980] and others. Most of them are theoretical studies based on the momentum theory with some empirical formulas for simulating the losses in the system units and the craft performances. Although these theoretical approaches give us useful informations on the primary stage of the system development, some refinements of the whole systems are necessary to obtain a best matching of the propulsion systems. It is noted that a choice of nozzle size is a powerful tool in optimizing the systems (Parker 1982).

In the present paper, experimental techniques for measuring the basic performances of the waterjet systems by the model experiment in a water tunnel are described. Based on the techniques, detail measurements of both the system and the unit performances are carried out with the thrust elbow arrangement and the optimization of the system performance is conducted by simulating the change of the nozzle outlet diameter with the variable nozzle arrangement.

\section{BASIC EQUATIONS}

A schematic diagram of the waterjet propulsion systems is shown in Fig. 1. It is consisted of the intake duct, the 
pump, and the nozzle, as usual. The thrust $\mathrm{T}$ of the waterjet craft is given by the reaction to the change of momentum of the water flow through the nozzle,

$$
\mathrm{T}=\rho \mathrm{Q}\left(\mathrm{V}_{\mathrm{j}}-\mathrm{V}_{\mathrm{i}}\right)
$$

where $V_{b}$ is the craft velocity, $V_{j}$ the jet velocity, $Q$ the volumetric flow rate and $\rho$ the density of the fluid. by,

The pressure head $\mathrm{H}$ developed by the pump is given

$$
\mathrm{H}=\mathrm{V}_{\mathrm{j}}^{2} /\left(2 \mathrm{~g} \eta_{\mathrm{j}}\right)-\left(1-\zeta_{\mathrm{i}}\right) \mathrm{V}_{\mathrm{b}}^{2} /(2 \mathrm{~g})
$$

where $\zeta_{\mathrm{i}}$ is the loss coefficient of the intake, $\eta_{\mathrm{j}}$ the nozzle efficiency and $g$ the gravitational acceleration. In this equation, the static pressure head between the intake and the nozzle are neglected because they are generally small in this propulsion.

The pump efficiency $\eta_{\mathrm{P}}$ and the propulsive efficiency $\eta_{\mathrm{v}}$ are defined as follows:

$$
\begin{gathered}
\eta_{\mathrm{P}}=\rho \mathrm{gQH} / \mathrm{P} \\
\eta_{v}=\mathrm{TV}_{\mathrm{b}} /(\rho \mathrm{gQH})
\end{gathered}
$$

where $\mathrm{P}$ is the power supplied to the pump.

The propulsive efficiency $\eta_{\mathrm{v}}$ is also expressed in a usually presented form with Eq. (1)-(3), as given by Parker [1982];

$\eta_{\mathrm{v}}=2 \mathrm{~V}_{\mathrm{rj}}\left(1-\mathrm{V}_{\mathrm{rj}}\right) /\left\{1 / \eta_{\mathrm{j}}-\left(1-\zeta_{\mathrm{i}} \mathrm{V}_{\mathrm{ri}}^{2}\right) \mathrm{V}_{\mathrm{rj}}^{2}\right\}$

where $V_{r j}$ is the jet velocity ratio $V_{b} / V_{j}$. It is noted that the intake loss coefficient $\zeta_{i}$ is a function of intake velocity ratio $\mathrm{V}_{\mathrm{ri}}\left(=\mathrm{V}_{\mathrm{i}} / \mathrm{V}_{\mathrm{b}}\right)$.

Neglecting the losses in the transmissions to be small, the overall efficiency $\eta$ is expressed as follows.

$$
\eta=\eta_{\mathrm{P}} \eta_{\mathrm{v}}
$$

\section{EXPERIMENTS}

\section{Waterjet Systems}

The waterjet systems used in the present experiment is $2 / 3$ scaled model of the prototype systems, which are consisted of intake, pump and nozzle, as illustrated in Fig. 1. Here, the flash type intake is used to minimize the intake drag. The test pump is a mixed flow type with a specific speed of $170\left(\mathrm{~m}^{3} / \mathrm{s}, \mathrm{m}, \mathrm{rpm}\right)$, which is selected from the theoretical optimization by Fujisawa et al. [1990] to

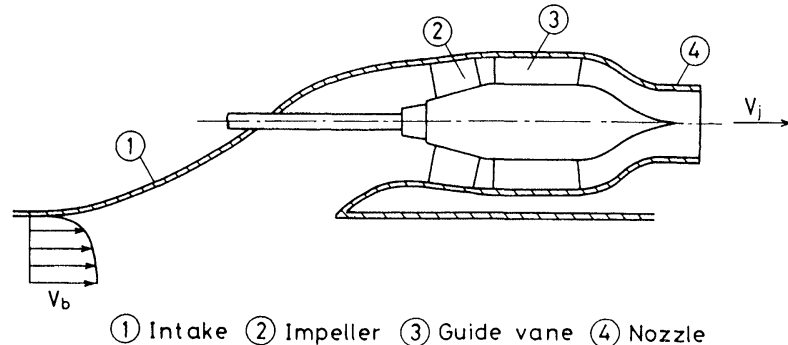

FIGURE 1 Schematic illustration of waterjet systems.

maximize the propulsive efficiency of the craft. The test rotor has three blades with sharp edges to improve the suction performance of the pump. The nozzle configuration is designed with no local separation and cavitation and with any desired exit velocity uniformity by Morel [1975]. Some more details about the waterjet systems for the prototype craft are given by Fujisawa et al. [1987] and Fujisawa and Ogawa [1992].

\section{Water Tunnel}

Figure 2 shows a water tunnel designed for the present experiment. The working fluid of water is filled in an underground tank of volume $4 \times 4 \times 2 \mathrm{~m}^{3}$. It is powered by a centrifugal pump of $15 \mathrm{~kW}$ and flows through the curved diffuser with corner vane, the straight diffuser (the outlet cross-sectional area $0.5 \times 0.5 \mathrm{~m}^{2}$ ), the settling chamber, and the contraction nozzle (the contraction ratio 11) to the test section, and it flows back into the underground tank. The cross-sectional area of the test section is $0.15 \times 0.15 \mathrm{~m}^{2}$ with its length of $1 \mathrm{~m}$. A control valve is attached to the exit of the outlet section in order to keep the static pressure in the test section to an atmospheric pressure in the experiment. The mean velocity $\mathrm{V}_{\mathrm{b}}$ in the test section is uniform with a nonuniformity less than 1 percent except the near wall region, and is controllable in a range of 2 to $7 \mathrm{~m} / \mathrm{s}$.

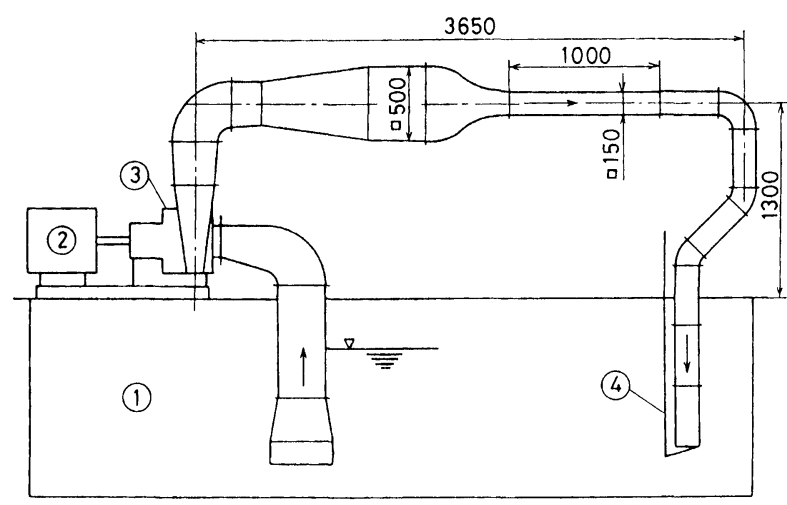

(1) Water tank (2) Motor (3) Pump (4) Valve

FIGURE 2 Water tunnel (Unit in $\mathrm{mm}$ ). 


\section{Measurement of Basic Performances}

Figure 3 shows an experimental arrangement for measuring the basic performances of the waterjet systems. The systems are attached flash to the side wall of the test section of the water tunnel. As an approaching boundary layer has a strong influence on the propulsive performances, the ratio $\delta_{1} / \mathrm{d}$ of the displacement thickness $\delta_{1}$ of the inlet boundary-layer to the outlet diameter $d$ of the intake is made equal to that of the field experiment by Fujisawa et al. [1987] with the prototype craft, which is $0.015 \pm 0.005$. However, the agreement of the Reynolds number is not achieved in the present experiment, that is the Reynolds number $\operatorname{Re}\left(=\mathrm{dV}_{\mathrm{b}} / v\right)=(1.2-4.1) \times 10^{5}$, while it is $(0.6-1.6) \times 10^{6}$ in the prototype experiment.

The torque performance of the pump is measured by a torque detector located between the pump and the motor of $0.75 \mathrm{~kW}$. The number of pump revolution $\mathrm{n}$ is detected by a photo sensor and the signals are measured by a pulse counter. The static-pressure measurement is carried out downstream of the pump guide vane, which allows the estimation of nozzle efficiency. The measurement is performed by a pressure transducer of strain-gauge type and a scanning-valve arrangement. The output signals are digitized by an $\mathrm{AD}$ converter and the time-averaging procedures are adopted in a microcomputer.

The thrust measurement is carried out using a thrust elbow arrangement shown in Fig. 3, which turns the direction of the jet-flow at right angles and ejects the flow to the underground tank. The resulting force caused by the momentum change is measured by a load detector in the downstream. The measured force $\left(=\rho Q^{2} / A_{j}\right)$ allows the estimation of the volumetric flow rate $\mathrm{Q}$ of the pump and the jet velocity $V_{j}$, and hence the thrust $T$ is estimated from Eq. (1), where $A_{j}$ is the nozzle outlet area and $\rho$ the density of fluid. The accuracy of the present thrust measurement is expected to within \pm 1 percent of the measured result, referring to Eilers and Shrout [1977].

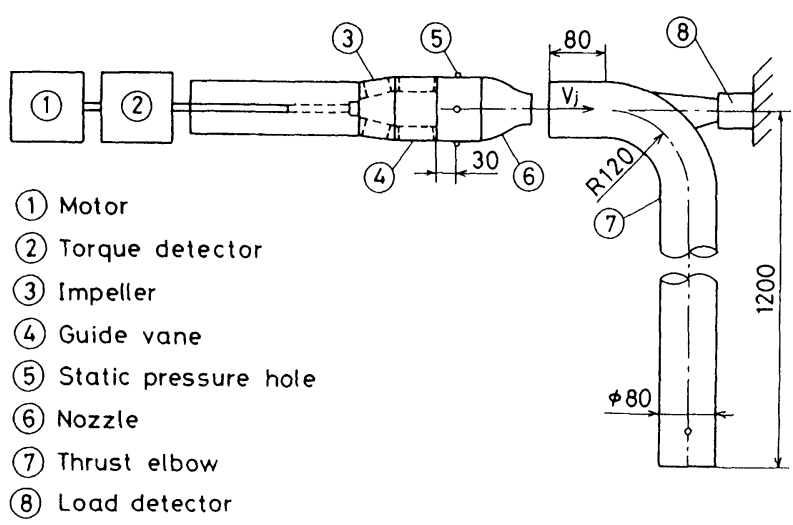

FIGURE 3 Experimental arrangement for measuring basic performances of waterjet systems (Unit in $\mathrm{mm}$ ).

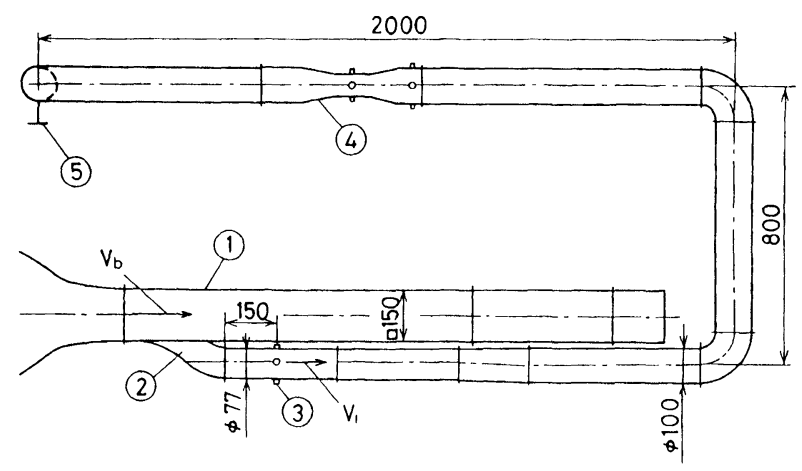

(1) Test section of water tunnel (2) Intake (3) Static pressure hole (4) Venturi tube (5) Valve

FIGURE 4 Experimental arrangement for measuring intake loss (Unit in $\mathrm{mm}$ ).

The intake loss is measured by an experimental arrangement as shown in Fig. 4. In this experiment, a pressure measuring section of length $300 \mathrm{~mm}$ is attached to the downstream end of the intake and the measurements are performed at the middle of the section, where the pressure distributions become rather uniform in circumferential directions. The volumetric flow rate $\mathrm{Q}$ is measured by a Venturi tube in the downstream. The intake velocity ratio $\mathrm{V}_{\mathrm{ri}}\left(=\mathrm{V}_{\mathrm{i}} / \mathrm{V}_{\mathrm{b}}\right)$ is controlled by a valve attached to the downstream end of the apparatus. These measurements allows the estimation of the pump head $\mathrm{H}$, the pump efficiency $\eta_{\mathrm{p}}$, the propulsive efficiency $\eta_{\mathrm{v}}$ and the overall efficiency $\eta$ with the aid of the basic equations of Eq. (2)-(6).

\section{Optimization of Waterjet Systems}

The performances of the waterjet systems are optimized by using an experimental apparatus shown in Fig. 5. The nozzle is simulated by the valve located at the downstream end of the apparatus. The working fluid of water

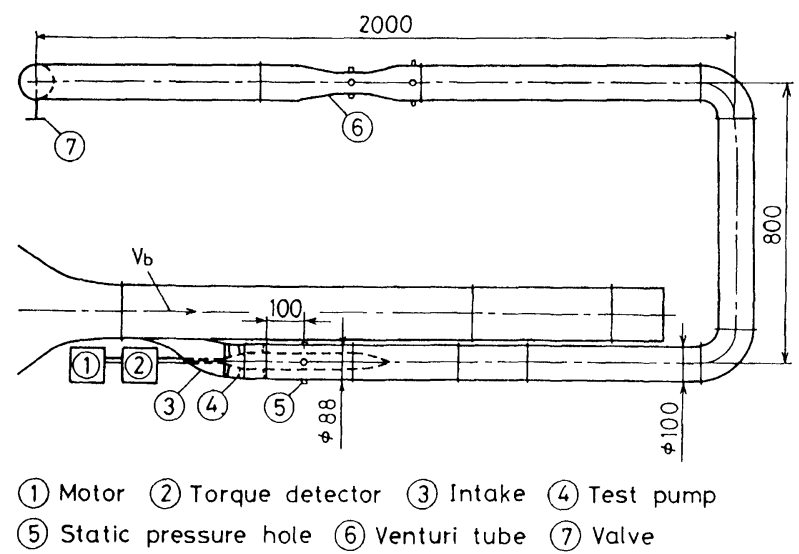

FIGURE 5 Experimental arrangement for optimizing performances of waterjet systems. 
is ejected from the valve to the water tank underground through the surrounding air. The torque performances of the pump is measured by a torque detector and the flow rate $\mathrm{Q}$ is obtained from the Venturi tube. The equivalent nozzle outlet diameter is estimated from the Bernoulli's equation assuming the nozzle losses are comparable to the losses in the test apparatus. Based on these measurements, all the pump and the propulsive performances are estimated from Eq. (1)-Eq. (6).

\section{Evaluation of Prototype Performances}

The performances of the prototype waterjet systems are evaluated by assuming geometric and dynamic similitudes of the measured results in the present experiment. The craft velocity $\mathrm{V}_{\mathrm{b}}{ }^{\prime}$, volumetric flow rate $\mathrm{Q}^{\prime}$ and the pressure head $\mathrm{H}^{\prime}$ in the prototype condition $\left(\mathrm{n}^{\prime}=6450 \mathrm{rpm}\right)$ are obtained from the following relations with $\mathrm{V}_{\mathrm{b}}, \mathrm{Q}, \mathrm{H}$, and $\mathrm{n}$ measured in the present model experiment;

$$
\begin{aligned}
& V_{b}^{\prime} / V_{b}=\left(n^{\prime} / n\right)\left(d^{\prime} / d\right) \\
& H^{\prime} / H=\left(n^{\prime} / n\right)^{2}\left(d^{\prime} / d\right)^{2} \\
& Q^{\prime} / Q=\left(n^{\prime} / n\right)\left(d^{\prime} / d\right)^{3}
\end{aligned}
$$

where the prime' denotes a value transformed into the prototype condition.

\section{RESULTS AND DISCUSSION}

\section{Pump Performances}

Figure 6 shows the pump performances of the waterjet systems measured by the thrust elbow arrangement, which are transformed into the prototype condition with the similarity relations Eq. (7)-Eq. (9). The results are compared with those of the field experiment by Fujisawa et al. [1987] with the prototype craft. It is seen that the flow rate $Q^{\prime}$ and the pump efficiency $\eta_{p}$ grows with the craft velocity $\mathrm{V}_{\mathrm{b}}{ }^{\prime}$, which suggests the effect of stagnation pressure acting on the intake front. On the other hand, the pressure head $\mathrm{H}^{\prime}$ in the present model experiment shows a decreasing trend with an increase in craft velocity $\mathrm{V}_{\mathrm{b}}{ }^{\prime}$, which is due to the effect of increased flow rate, while it is not observed in the field experiment due to the data scattering. It is expected that the scattering of the data in the field experiment is mainly caused by the effects of waviness of water surfaces and the inevitable winds in the test fields. The results also suggest the improved accuracy in the present model experiment. It should be mentioned that all the pump characteristics show abrupt decrease at small craft velocity $\mathrm{V}_{\mathrm{b}}{ }^{\prime}$ because of the occurrence of cavitation, which is not reproduced in the model experiment due to the low Reynolds numbers.

\section{Propulsive Performances}

Figure 7 shows the propulsive performances of the waterjet systems measured in the present experiment, which are compared with the field experiment by Fujisawa et al. [1987] with the prototype craft. It is seen that both the results are in reasonable agreement with each other within an experimental uncertainty. Although the thrust performance in the field experiment shows the effect of cavitation at small craft velocity, a decreasing trend in the thrust $\mathrm{T}$ with increasing $\mathrm{V}_{\mathrm{b}}{ }^{\prime}$ is well reproduced in most of the craft velocity range as is expected in Eq. (1). This decreasing trend comes up to the craft

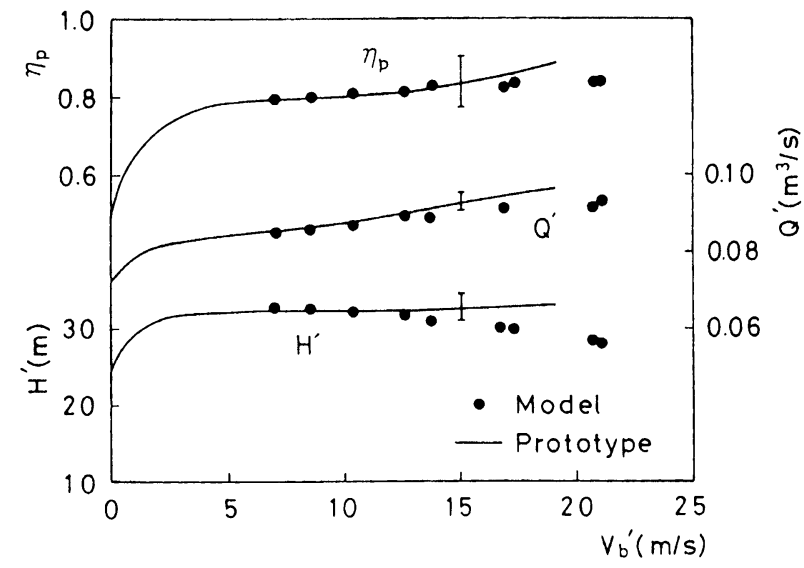

FIGURE 6 Pump performances of waterjet systems in relation to craft velocity $\mathrm{V}_{\mathrm{b}}{ }^{\prime}$.

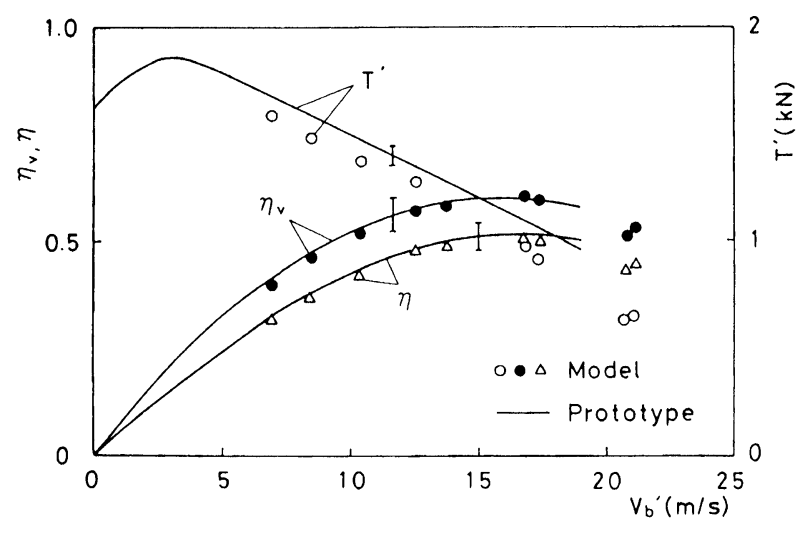

FIGURE 7 Propulsive performances of waterjet systems in relation to craft velocity $\mathrm{V}_{\mathrm{b}}{ }^{\prime}$. 
velocity where it balances the drag of the craft. The propulsive efficiency $\eta_{\mathrm{v}}$ and the overall efficiency $\eta$ show increasing trend at small craft velocity and they reach their maximums at the craft velocity $V_{b}{ }^{\prime}=16$ $17 \mathrm{~m} / \mathrm{s}$. For further large craft velocity, they decrease gradually.

\section{Intake Loss Coefficient and Nozzle Efficiency}

Figure 8 shows the intake loss coefficient $\zeta_{\mathrm{i}}\left(=2\left(\mathrm{p}_{\mathrm{t} \propto}-\mathrm{p}_{\mathrm{ti}}\right) /\right.$ $\left.\left({ }_{\rho} V_{i}^{2}\right)\right)$ obtained from the present experiment, which is expressed in relation to the intake velocity ratio $V_{r i}$ $\left(=\mathrm{V}_{\mathrm{i}} / \mathrm{V}_{\mathrm{b}}\right)$, where $\mathrm{p}_{\mathrm{t} x}$ is a total pressure measured at the upstream of the intake and $p_{t i}\left(=p_{i}+\rho V_{i}^{2}\right)$ is that at the downstream of the intake, with $\mathrm{p}_{\mathrm{i}}$ the measured staticpressure downstream of the intake. The results shown in this figure are obtained at 6 different main flow velocities $\mathrm{V}_{\mathrm{b}}$ in a range of $2-6 \mathrm{~m} / \mathrm{s}$. It is clear that the intake loss coefficient $\zeta_{\mathrm{i}}$ depends mainly on the intake velocity ratio $\mathrm{V}_{\mathrm{ri}}$ and the effect of Reynolds number on $\zeta_{\mathrm{i}}$ is negligibly small in the present range of Reynolds numbers. The intake loss coefficient takes a minimum around the velocity ratio of 1 . The increases in the intake loss coefficient at small velocity ratio is caused by the flow separation, as is shown by the flow visualization study by Fujisawa et al. [1990]. While the increases in $\zeta_{\mathrm{i}}$ at large intake velocity ratio are due to the increases in frictional losses.

The measured nozzle efficiency $\eta_{\mathrm{j}}\left(=\rho \mathrm{V}_{\mathrm{j}}^{2} /\left(2 \mathrm{p}_{\mathrm{tn}}\right)\right)$ is plotted against the nozzle reduction ratio $\mathrm{C}$ in Fig. 9, where the nozzle reduction ratio is defined as the ratio of the outlet area to the inlet area of the nozzle and $p_{t n}$ is a total pressure upstream of the nozzle. It is seen that the nozzle efficiency is roughly constant but it decreases slightly with an increase in nozzle reduction ratio, which

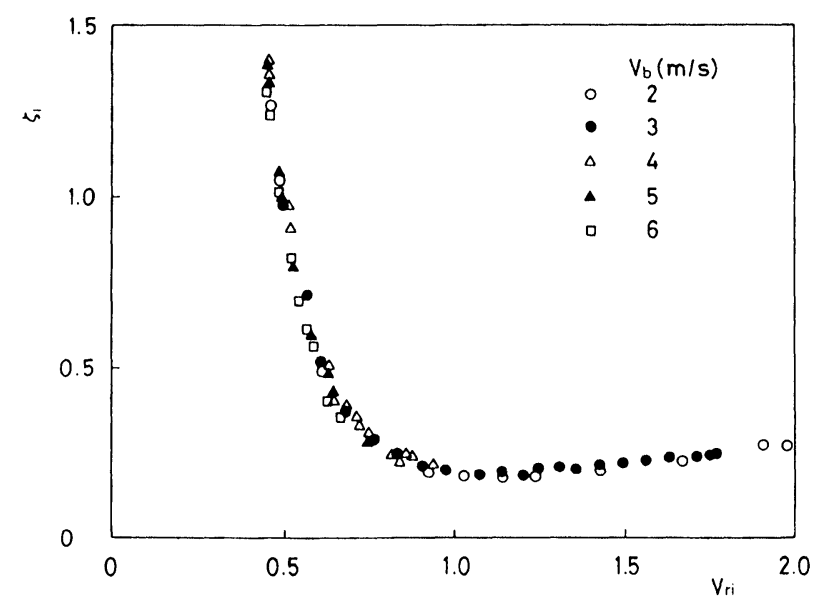

FIGURE 8 Intake loss coefficient $\zeta_{\mathrm{i}}$ versus intake velocity ratio $\mathrm{V}_{\mathrm{ri}}$.

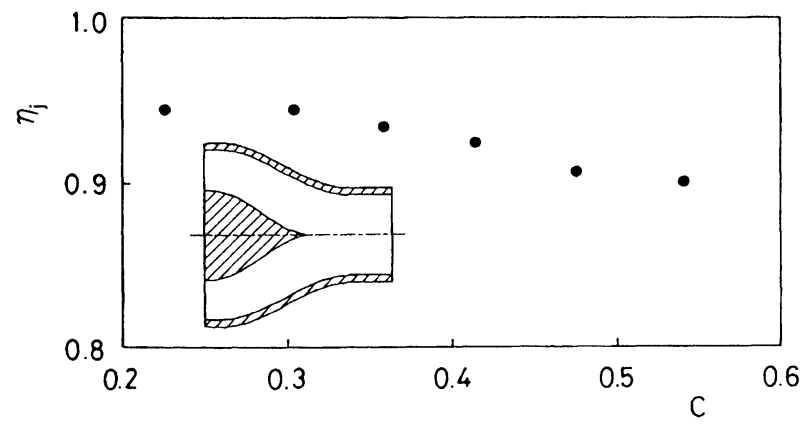

FIGURE 9 Nozzle efficiency $\eta_{j}$ versus nozzle reduction ratio C.

might be due to the possible separation of the nozzle flow by the reduction in the flow acceleration.

\section{Performances of Water Jet Systems in Variable Nozzle Arrangement}

Figure 10 shows the pump performances of the waterjet systems in relation to the nozzle outlet diameters $d_{j}{ }^{\prime}$ in the prototype conditions, which are measured by the present water tunnel experiment with variable nozzle arrangement. The results are compared with that of the thrust elbow arrangement with 5 nozzles of different outlet diameters. Two typical results are shown for the craft velocity $\mathrm{V}_{\mathrm{b}}{ }^{\prime}=6.9 \mathrm{~m} / \mathrm{s}$ (a) and $\mathrm{V}_{\mathrm{b}}{ }^{\prime}=20.7 \mathrm{~m} / \mathrm{s}$ (b). It is clearly seen that the pump performances measured by the variable nozzle arrangement agree closely with those by the thrust elbow arrangement. This result indicates the possible measurement of the pump performances by the variable nozzle arrangement. The result also indicates that the pump head $\mathrm{H}^{\prime}$ decreases and the flow rate $\mathrm{Q}^{\prime}$ increases as the nozzle outlet diameter $d_{j}{ }^{\prime}$ is increased. While, the pump efficiency $\eta_{\mathrm{p}}$ reaches a maximum at a certain value of the nozzle diameter $d_{j}{ }^{\prime}$, suggesting the presence of an optimum outlet diameter of the nozzle to maximize the pump efficiency. It is seen that the optimum nozzle diameter becomes smaller as the craft velocity increases.

Figure 11 shows the propulsive performances of the waterjet systems measured by the variable nozzle arrangement in relation to the nozzle outlet diameters $d_{j}{ }^{\prime}$, which are compared with the thrust elbow results at the same craft velocities. All the propulsive performances measured by the variable nozzle arrangement agree closely with those by the thrust elbow arrangement, as is observed in the measurement of pump performances. It is considered that all the propulsive performances reach the maximums at certain values of nozzle outlet diameter $d_{j}{ }^{\prime}$. The propulsive efficiency $\eta_{\mathrm{v}}$ at $\mathrm{V}_{\mathrm{b}}{ }^{\prime}=6.9 \mathrm{~m} / \mathrm{s}$ is expected to have a peak at the nozzle outlet diameter $d_{j}{ }^{\prime}$ larger than 0.1 . The thrust curve shows a maximum at relatively 

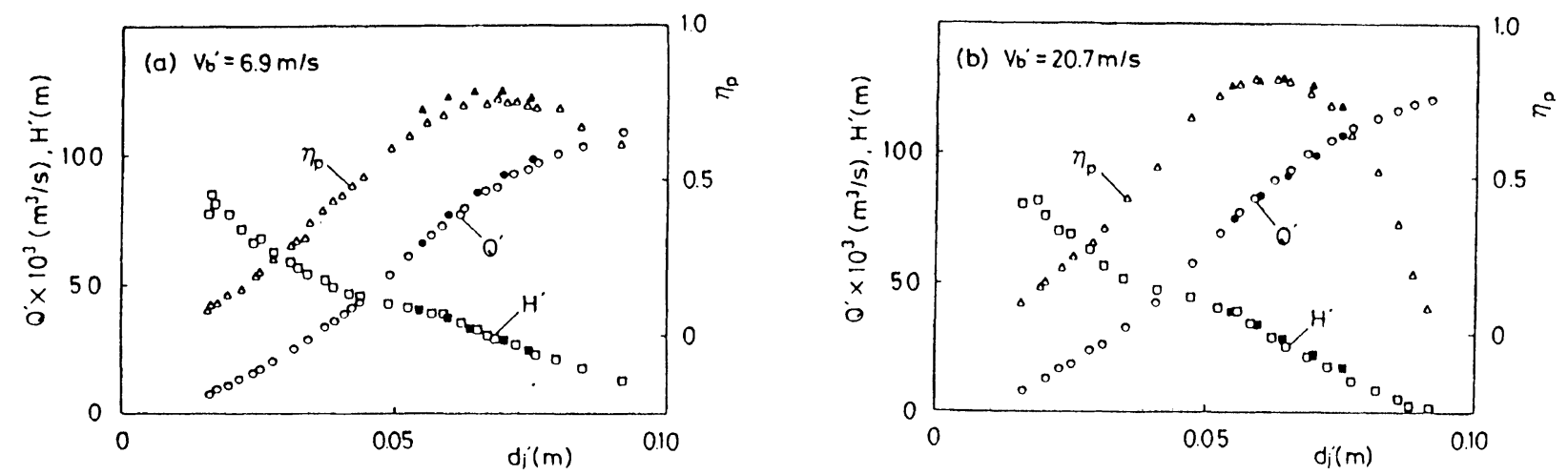

FIGURE 10 Variations of pump performances with nozzle outlet diameter $\mathrm{d}_{\mathrm{j}}{ }^{\prime}(\bigcirc \triangle \square$ : Variable nozzle arrangement, arrangement).

small nozzle diameters and the propulsive efficiency reaches a maximum at relatively large nozzle diameters, and the maximum of the overall efficiency lies between them. On the other hand, all the propulsive performances are strongly affected by the craft velocity $\mathrm{V}_{\mathrm{b}}{ }^{\prime}$, as is seen in the deviations of the optimum nozzle diameters at $\mathrm{V}_{\mathrm{b}}{ }^{\prime}=6.9 \mathrm{~m} / \mathrm{s}$ and $20.7 \mathrm{~m} / \mathrm{s}$. Therefore, it can be considered that the optimum nozzle diameters decrease as the craft velocity $\mathrm{V}_{\mathrm{b}}{ }^{\prime}$ is increased, similar to the case of the pump performances.

\section{Optimum Performances of Waterjet Systems}

Figure 12 shows the optimum pump efficiency $\eta_{\mathrm{po}}$ in relation to the craft velocity $\mathrm{V}_{\mathrm{b}}{ }^{\prime}$, and the corresponding variations of the nozzle outlet diameters $\mathrm{d}_{\mathrm{jo}}{ }^{\prime}$ and the jet velocity ratio $V_{\text {rjo }}$, which are obtained from the measurements at two numbers of pump revolution, that is $\mathrm{n}=2300 \mathrm{rpm}$ and $2800 \mathrm{rpm}$. It is seen that the nozzle diameters $\mathrm{d}_{\mathrm{jo}}{ }^{\prime}$ at the optimum condition are decreased as the craft velocity $\mathrm{V}_{\mathrm{b}}{ }^{\prime}$ increases and the corresponding increases in the jet velocity ratio $\mathrm{V}_{\text {rjo }}$ is observed. The optimum pump efficiency $\eta_{\mathrm{po}}$ increases gradually as the craft velocity $V_{b}{ }^{\prime}$ increases, which shows the improvement in the pump efficiency by the stagnation effect of free stream.

Figure 13 shows the optimum propulsive efficiency $\eta_{\mathrm{vo}}$ in relation to the craft velocity $\mathrm{V}_{\mathrm{b}}{ }^{\prime}$, and the corresponding variations of the nozzle outlet diameters $d_{j o}{ }^{\prime}$ and the jet velocity ratios $\mathrm{V}_{\text {rijo }}$. It is observed that the optimum nozzle diameters $\mathrm{d}_{\mathrm{jo}}{ }^{\prime}$ are decreased as the craft velocity $V_{b}{ }^{\prime}$ increases to maximize the propulsive efficiency. This result is qualitatively similar to that observed in the optimum pump efficiency, but the decreasing rate of the optimum nozzle diameter with the craft velocity is larger than the case of the pump efficiency.
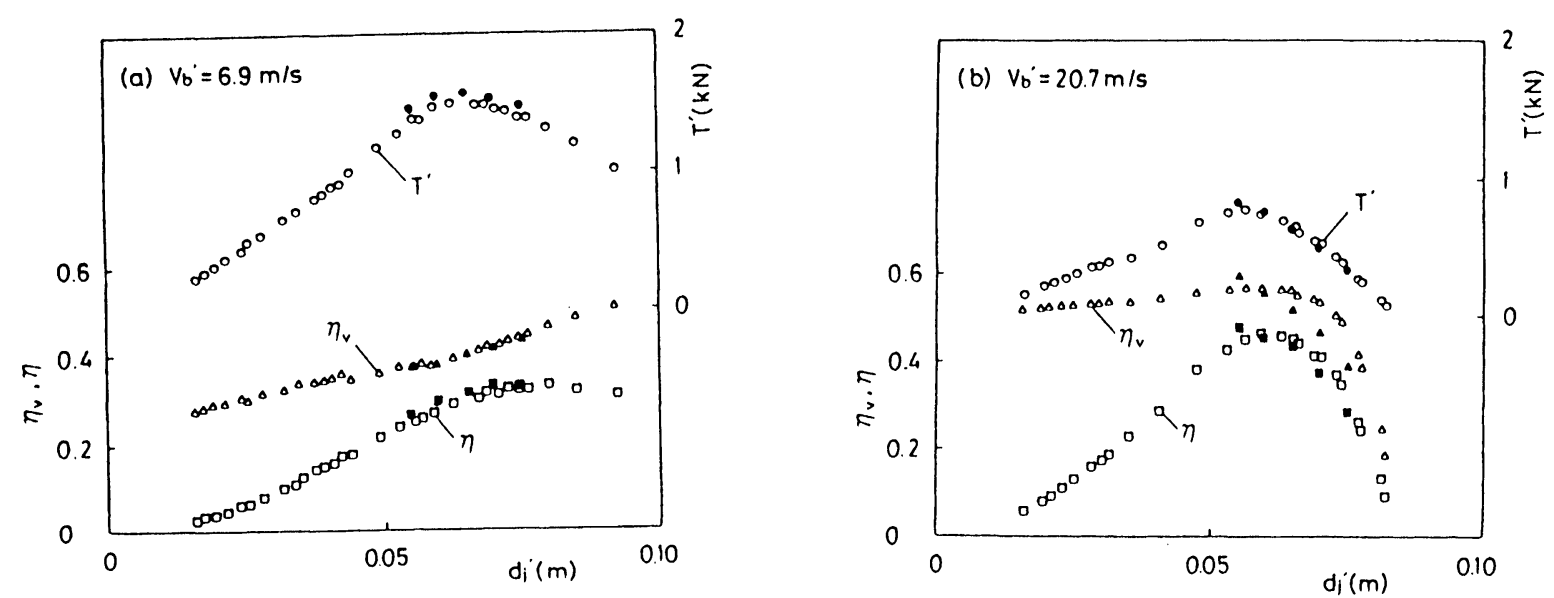

FIGURE 11 Variations of propulsive performances with nozzle outlet diameter $\mathrm{d}_{\mathrm{j}}{ }^{\prime}(\bigcirc \triangle \square$ : Variable nozzle arrangement, $\bullet \mathbf{\Delta} \boldsymbol{\square}$ : Thrust elbow arrangement). 


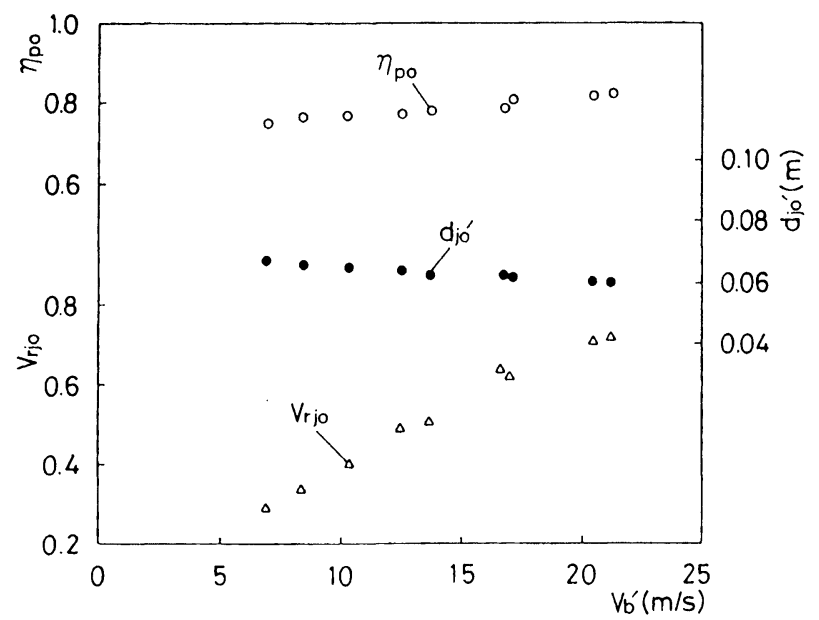

FIGURE 12 Optimum pump efficiency $\eta_{\mathrm{po}}$ versus craft velocity $\mathrm{V}_{\mathrm{b}}$ '.

Hence, the increasing rate of the jet velocity ratio $V_{\text {rjo }}$ with the craft velocity is smaller than the case of the pump efficiency. The optimum propulsive efficiency shows a maximum at the craft velocity $V_{b}=13 \mathrm{~m} / \mathrm{s}$, which shows the presence of the optimum velocity of the craft to maximize the optimum propulsive efficiency. As the propulsive efficiency of the waterjet systems is mainly governed by the jet velocity ratio $\mathrm{V}_{\mathrm{rj}}$, which is a function of the specific speed of the pump, an optimum value of the pump specific speed should be selected to match with the maximum propulsive efficiency at the designed craft velocity, as is mentioned by Fujisawa et al. [1990].

Figure 14 indicates the optimum overall efficiency $\eta_{\mathrm{o}}\left(=\eta_{\mathrm{p}} \eta_{\mathrm{v}}\right)$ in relation to the craft velocity $\mathrm{V}_{\mathrm{b}}{ }^{\prime}$ and the corresponding variations of the nozzle outlet diameter $\mathrm{d}_{\mathrm{jo}}{ }^{\prime}$ and the jet velocity ratios $\mathrm{V}_{\mathrm{rjo}}$. It is mentioned that the optimum craft velocity at the maximum of the optimum overall efficiency is shifted to a higher craft

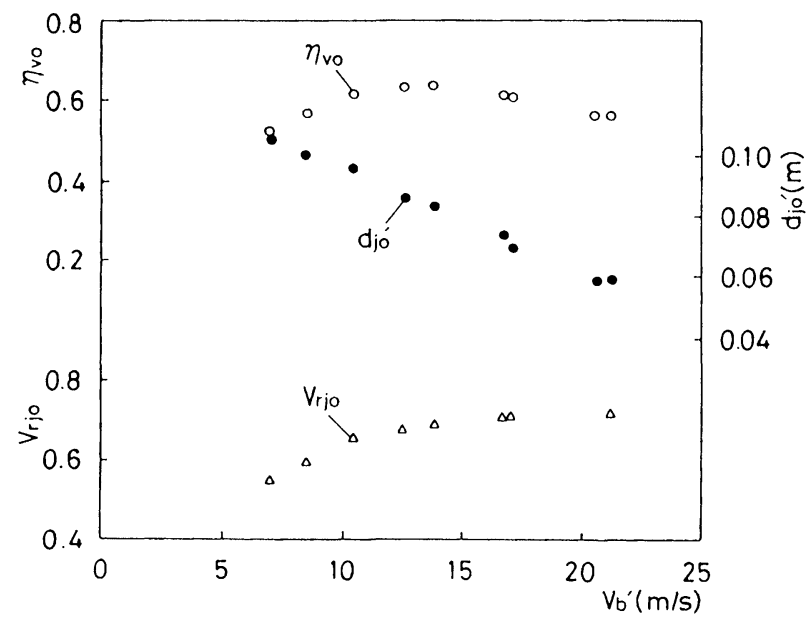

FIGURE 13 Optimum propulsive efficiency $\eta_{\mathrm{v}}$ versus craft velocity $\mathrm{V}_{\mathrm{b}}{ }^{\prime}$.

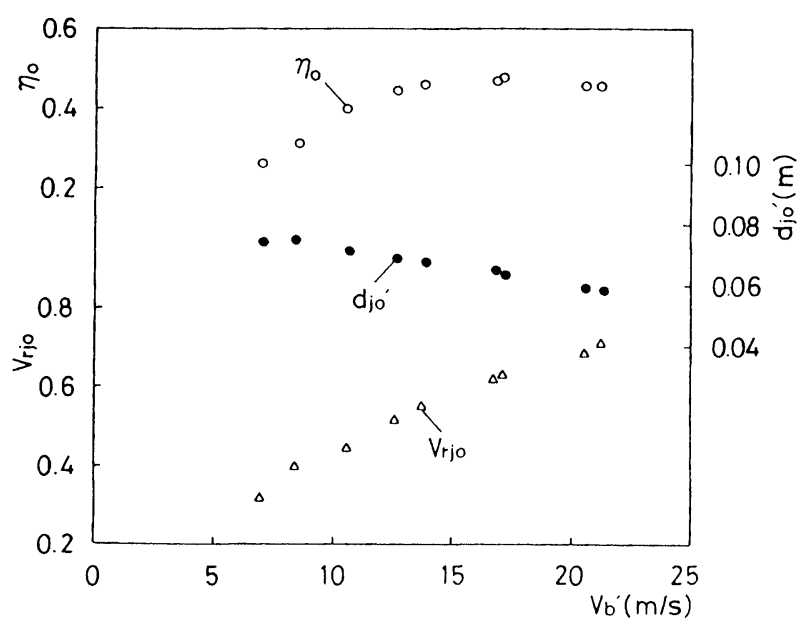

FIGURE 14 Optimum overall efficiency $\eta$ versus craft velocity $V_{b}{ }^{\prime}$.

velocity $V_{b}{ }^{\prime}=16 \mathrm{~m} / \mathrm{s}-17 \mathrm{~m} / \mathrm{s}$ than that of the propulsive efficiency due to the improvement in the pump efficiency at high craft velocity.

\section{CONCLUSIONS}

Experimental techniques for evaluating the performances of waterjet propulsion systems using a water tunnel is described to investigate into the system and unit performances and the optimization of the system performances. The results are summarized as follows:

(1) The performances of the waterjet systems such as the pump and the propulsion are measured in the water tunnel with thrust elbow arrangement. The results are in close agreement with the field experiment with the improved accuracy of the data.

(2) The measurement of the losses in the intake and the nozzle of the waterjet systems is performed. The intake loss coefficient varies with the intake velocity ratio, having a minimum around the velocity ratio of 1 , while the nozzle efficiency is roughly constant but decreases slightly as the nozzle reduction ratio increases.

(3) The optimization of the system performances is carried out using the water tunnel experiment with variable nozzle arrangement. The presence of the optimum nozzle diameters is indicated to maximize the pump and the propulsive efficiencies of the waterjet craft. As the craft velocity is increased, the optimum nozzle diameters are decreased.

(4) The optimum pump efficiency increases gradually with the craft velocity, while the optimum propulsive efficiency shows a maximum at a certain craft velocity, suggesting a matching of the specific speed of the pump with the designed velocity of the craft. 


\section{Acknowlegments}

The author would like to thank Mr. Ishihara, T., Mr. Gotoh H. and Mr. Kawabata, T. of Yamato motor company and Mr. Ogawa, H. of Suzuki motor company for their cooperation to the present experiments.

\begin{tabular}{lll}
\multicolumn{2}{l}{ Nomenclature } & \\
$C$ & $:$ & nozzle reduction ratio \\
$d$ & $:$ & exit diameter of intake \\
$H$ & $:$ & pressure head of pump \\
$n$ & $:$ & number of pump revolution \\
$P$ & $:$ & supplied power to pump \\
$Q$ & $:$ & volumetric flow rate \\
$R_{e}$ & $:$ & Reynolds number $\left(=\mathrm{dV}_{\mathrm{b}} / \nu\right)$ \\
$T$ & $:$ & thrust \\
$V_{b}$ & $:$ & craft velocity \\
$V_{i}$ & $:$ & velocity at intake exit \\
$V_{j}$ & $:$ & velocity at nozzle exit \\
$V_{r i}$ & $:$ & intake velocity ratio $\left(=\mathrm{V}_{\mathrm{i}} / \mathrm{V}_{\mathrm{b}}\right)$ \\
$V_{r j}$ & $:$ & jet velocity ratio $\left(=\mathrm{V}_{\mathrm{b}} / \mathrm{V}_{\mathrm{j}}\right)$ \\
$\delta_{l}$ & $:$ & displacement thickness of inlet boundary-layer \\
$\zeta_{i}$ & $:$ & intake loss coefficient \\
$\eta$ & $:$ & overall efficiency $\left(=\eta_{\mathrm{p}} \eta_{\mathrm{v}}\right)$ \\
$\eta_{j}$ & $:$ & nozzle efficiency \\
$\eta_{p}$ & $:$ & pump efficiency \\
$\eta_{1}$ & $:$ & propulsive efficiency \\
$\nu$ & $:$ & kinematic viscosity of fluid \\
$\rho$ & $:$ & density of fluid
\end{tabular}

\section{Superscript}

variable transformed to prototype condition

\section{References}

Barr, R.A. and Etter, R.J., 1975. Selection of Propulsion Systems for High-Speed Advanced Marine Vehicles, Marine Technology, Vo. 12, pp. 33-49.
Brandau, J.H., 1968. Performance of Waterjet Propulsion Systems; A Review of the State-of-the-art, J. Hydronautics, Vol. 2, pp. 61-73.

Eilers, R.E. and Shrout, L.S., 1977. Waterjet Propulsor Thrust Measurement Using a Reaction Elbow, Proc. 18th ATTC, Annapolis, pp. 251-261.

Etter, R.J., 1976. Waterjet Propulsion; An Overview, Marine Propulsion, Vol. 2, Ed. Sladky, J., pp. 97-128, ASME, N.Y.

Etter, R.J., Krishnamoorthy, V. and Sherer, J.O., 1980. Model Testing of Waterjet Propelled Craft, Proc. 19th ATTC, Ann Abor, pp. 783-806. Fujisawa, N., Shirai, H., Uchiyama, K, Gotoh, H. and Kawabata, T., 1987. Measurement of Propulsion-Performance in Acceleration of High-Speed Hydroplane Boat with Waterjet Drive, Turbomachinery, Vol. 15, pp. 696-700 (in Japanese).

Fujisawa, N., Takebe, T. and Shirai, H., 1990. Optimum Design of Waterjet Propulsion Systems for High-Speed Hydroplane Boat, Proc. 3rd Japan-China Joint Conf. Fluid Machinery, Osaka, Vol. 2, pp. 17-24.

Fujisawa, N., Tabei, M. and Shirai, H., 1990. Measurement and Flow Visualization Study on the Basic Performance of the Intake for Waterjet Propulsion, Turbomachinery, Vol. 18, no. 2, pp. 86-93 (in Japanese).

Fujisawa, N. and Ogawa, H., 1992. Model and Prototype Performances of Waterjet Propulsion Systems for Small-Scale High-Speed Hydroplane Boat, Proc. 4th Int. Symp. Transport Phenomena and Dynamics of Rotating Machinery, Honolulu, pp. 259-268.

Haglund, K., Svensson, R. and Bjorheden, O., 1982. Design and Testing of a High-Performance Water Jet Propulsion Unit, Proc. 2nd Small Fast Warships and Security Vessels, London, pp. 223-237.

Kashiwadani, T., 1985. The Study on the Configurations of Waterjet Inlet (1st Report), J. SNAJ, No. 157, pp. 131-140 (in Japanese).

Kashiwadani, T., 1986. The Study on the Configurations of Waterjet Inlet (2nd Report), J. SNAJ, No. 159, pp. 118-128 (in Japanese).

Morel, T., 1975. Comprehensive Design of Axisymmetric Wind Tunnel Contractions, ASME J. Fluids Eng., Vol. 97, pp. 225-233.

Parker, R.G., 1982. Water Jet Drive; Aspects of Design and Use, and It's Place among Propulsion Systems, Proc. Propulsion Small Craft Propellers, Sterngear, Paper 10.

Wilson, M.B., 1977. A Survey of Propulsion-Vehicle Interactions on High-Performance Marine Craft, Proc. 18th ATTC, Annapolis, pp. 201-249. 

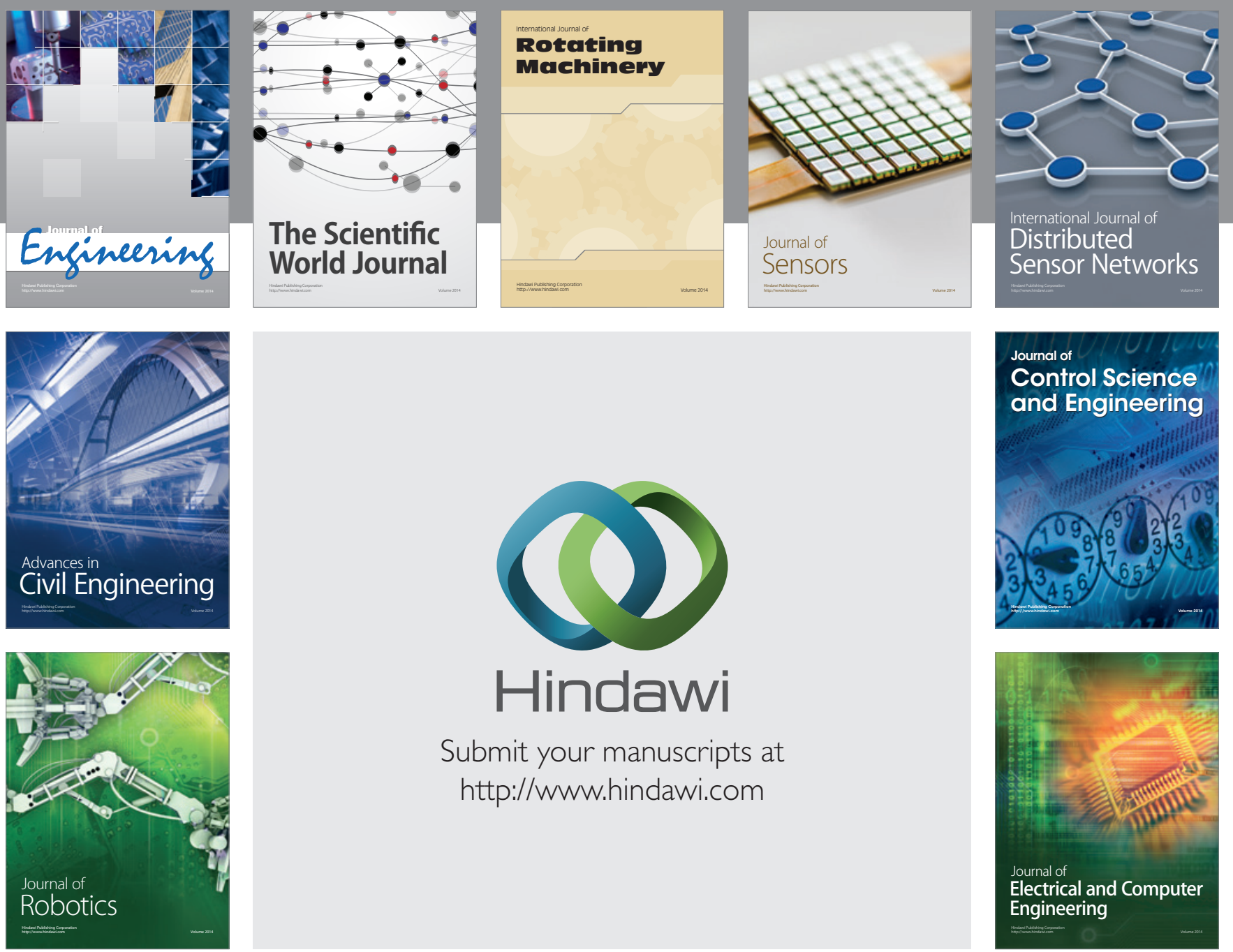

Submit your manuscripts at

http://www.hindawi.com
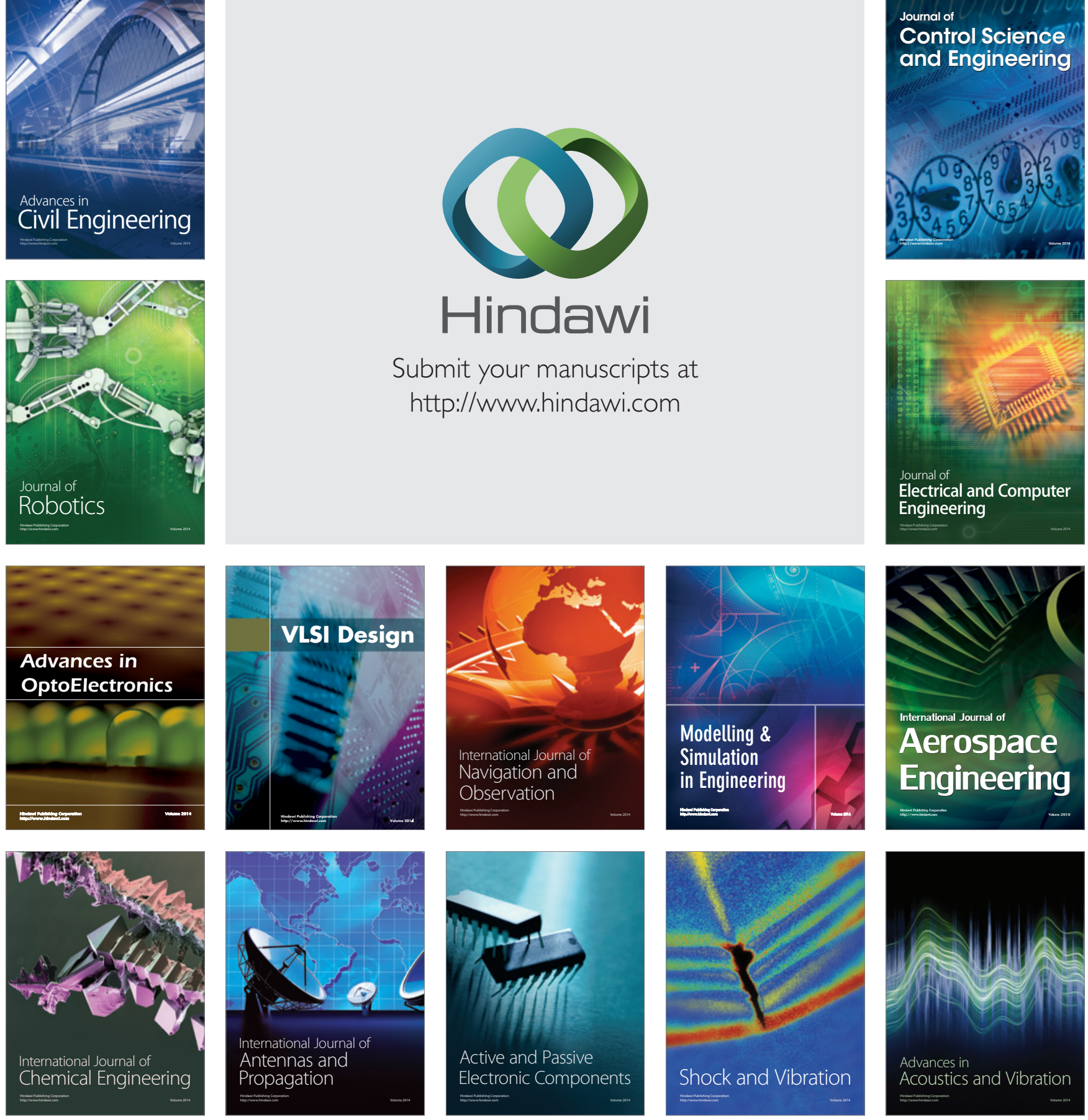